\title{
Colonoscopy with Polypectomy in Patients Taking Clopidogrel
}

\author{
Shai Friedland ${ }^{\mathrm{a}, \mathrm{b}}$, Cynthia W Leung ${ }^{\mathrm{a}}$, Roy M Soetikno ${ }^{\mathrm{a}}$
}

\begin{abstract}
Background: To investigate the bleeding risk of colonoscopy with polypectomy in patients taking clopidogrel.

Methods: Retrospective review of patients undergoing colonoscopy with polypectomy without interruption of clopidogrel. Patients with lesions larger than $1 \mathrm{~cm}$ were generally rescheduled for polypectomy off clopidogrel. Most of the polyps were removed using cold snare technique. Endoscopic clips were routinely applied prophylactically.
\end{abstract}

Results: A total of 125 polypectomies were performed in 60 patients. The average polyp size was $5.4 \pm 2.1 \mathrm{~mm}$. One patient $(1.7 \%$, CI $0.3-8.9 \%$ ) developed post-polypectomy bleeding that resolved without treatment. Three patients $(5 \%$, CI $1.7-14 \%)$ had immediate bleeding during the procedure and all resolved with prompt clip application.

Conclusions: Polypectomy of lesions up to $1 \mathrm{~cm}$ in size can be performed without interruption of clopidogrel.

Keywords: Colonoscopy; Colon cancer; Colon polyp; Polypectomy; Antiplatelet drug

\section{Introduction}

Clopidogrel is a thienopyridine derivative that irreversibly inhibits platelet activation and aggregation [1]. It is

\footnotetext{
Manuscript accepted for publication August 11, 2009

aDepartment of Gastroenterology, VA Palo Alto Health Care System and Stanford University, Palo Alto, California, USA.

${ }^{\mathrm{b} C}$ Corresponding author: Department of Gastroenterology, VA Palo Alto. 3801 Miranda Drive, Palo Alto, CA 94304, USA.

Email: shai_friedland@yahoo.com
}

doi:10.4021/gr2009.08.1308 commonly used to reduce thrombotic events, particularly in patients who have undergone coronary stent placement $[2$, 3]. Temporary discontinuation of clopidogrel, particularly in patients who have undergone coronary stent placement within 3 - 6 months, is generally considered inadvisable unless there is a compelling indication [4]. When clopidogrel is stopped to perform surgery or endoscopy, a 7 - 10 day period is generally recommended to allow time for adequate replacement of the platelet pool [4]. However, there is a general lack of consensus in the literature as to the optimal strategy for balancing the risk of increased bleeding if clopidogrel is continued perioperatively and the risk of thrombotic events if it is interrupted [4,5]. This ambiguity is also present in the 2005 American Society of Gastrointestinal Endoscopy guidelines for endoscopic procedures: for "high risk" procedures such as colonoscopic polypectomy, the guidelines state that "Whether to discontinue these agents has not been determined [6]." One of the fundamental difficulties with deciding how to manage clopidogrel in patients undergoing colonoscopy is that the risk of post-polypectomy bleeding in this setting is not known [6-8]. Our anecdotal experience has suggested that the bleeding risk is not exceptionally high when small polyps are resected, and based on this we have been routinely performing polypectomy of lesions up to 1 $\mathrm{cm}$ in size without interruption of clopidogrel [9].

\section{Materials and Methods}

A retrospective chart review was conducted on patients undergoing colonoscopic polypectomy without interruption of clopidogrel between January 2007 and August 2008 at the VA Palo Alto Health Care System. The study was conducted with institutional review board approval. Our standard clinical practice, which was followed in all but 3 cases, was to perform polypectomy of lesions up to $1 \mathrm{~cm}$ in size in these patients. Polyp size was estimated by comparison to a $10 \mathrm{~mm}$ snare or an opened biopsy forceps. Patients with larger lesions were rescheduled in order to perform polypectomy after interruption of clopidogrel for 1 week. In 3 cases, polyps larger than $1 \mathrm{~cm}$ were removed, and these patients were also included in the series. In all patients, immediately follow- 
Table 1. Patient Characteristics

\begin{tabular}{ll} 
Number of Patients & 60 \\
Male (Female) & $60(0)$ \\
Average Age (Std Dev) & $64.7(8.1)$ \\
Indication for Colonoscopy (\%) & \\
$\quad$ Prior polyp or cancer & $24(40 \%)$ \\
Screening & $23(38 \%)$ \\
$\quad$ Iron deficiency anemia & $6(10 \%)$ \\
$\quad$ Bleeding & $3(5 \%)$ \\
Other & $4(7 \%)$ \\
Indications for Clopidogrel (\%) & \\
Coronary stent & $38(63 \%)$ \\
Stroke or transient ischemic attack & $18(30 \%)$ \\
Peripheral vascular disease & $5(8 \%)$ \\
Coronary disease without stent & $3(5 \%)$ \\
Concomitant Use of Other Medications (\%) & \\
Aspirin & $10(17 \%)$ \\
Warfarin (held for 36 hours) & $2(3 \%)$ \\
\hline
\end{tabular}

ing polypectomy, one or more endoscopic clips were placed prophylactically to close the polypectomy defect. Immediate bleeding was diagnosed when the endoscopist noted excessive (more than $20 \mathrm{ml}$ ) bleeding between the polypectomy and the placement of endoscopic clips. All patients were followed-up by telephone or in clinic at least 1 week after the procedure.

\section{Results}

A total of 125 polypectomies were performed in 60 patients. Patient characteristics are described in Table 1. All of the patients were male, with an average age of 65 . The majority of the colonoscopies, $78 \%$, were performed on asymptomatic patients in our colorectal cancer screening/ surveillance program, $63 \%$ of the patients were taking clopidogrel because of prior placement of coronary stents, $30 \%$ were taking the medication to prevent recurrent cerebrovascular events.

The polyps that were removed ranged in size from 3 to $12 \mathrm{~mm}$, with an average diameter of $5.4 \mathrm{~mm}$ (Table 2). Most of the polyps were removed either using cold snare technique [10] (snare without cautery) or by endoscopic mucosal resection [11] (snare with cautery following submuco- sal injection of saline). There were 3 episodes of immediate bleeding (5\% of patients, CI 1.7-14\%); all were successfully treated by endoclip application and did not require hospital admission or observation. There was 1 episode of delayed bleeding (1.7\% of patients, CI $0.3-8.9 \%)$ that occurred 36 hours following resection of a $5 \mathrm{~mm}$ and a $6 \mathrm{~mm}$ adenoma by endoscopic mucosal resection. The patient had four grossly bloody bowel movements at home, but did not seek medical attention. The bleeding resolved without treatment. Photographs from the procedure were reviewed and no obvious irregularities in technique were observed. Both polypectomy sites appeared to have been clipped adequately at the time of the procedure.

\section{Discussion}

Clopidogrel is widely used for prevention of thrombotic events, particularly in patients who have undergone coronary stenting [12-14]. Optimal management of these patients requires knowledge of the bleeding risks associated with continuation of clopidogrel during colonoscopic polypectomy and the thrombotic risks that patients are exposed to if the medication is interrupted. While there has been significant attention paid to the potential risk of stopping clopidogrel in coronary stent patients, the bleeding risk associated with polypectomy has not been quantified systematically [15-17]. This retrospective series of 60 patients demonstrates that the risk of major bleeding is low. Only 1 patient $(1.7 \%$, CI $0.3-8.9 \%$ ) had significant post-polypectomy bleeding, which

Table 2. Polypectomy Characteristics

\begin{tabular}{ll}
\hline Number of Polyps & 125 \\
Polyps per patient (range) & $2.1(1-7)$ \\
Average Size (Std Dev) & $5.4 \mathrm{~mm}(2.1 \mathrm{~mm})$ \\
Size Range & $3-12 \mathrm{~mm}$ \\
Polypectomy Technique & \\
$\quad$ Snare without cautery & $91(73 \%)$ \\
Snare with cautery after saline injection & $27(22 \%)$ \\
Snare without cautery after saline injection & $3(2 \%)$ \\
Biopsy forceps without cautery & $3(2 \%)$ \\
Snare with cautery after endoloop & $1(1 \%)$ \\
Histology & $13(10 \%)$ \\
Adenoma & $98(78 \%)$ \\
Non-neoplastic & \\
Specimen lost & \\
\hline
\end{tabular}


was self limited and resolved without hospital admission. There were 3 episodes of immediate bleeding, all of which stopped with prompt clip application. This is rather subjective, as there is often some bleeding immediately after snaring of polyps when minimal or no cautery is utilized. However, the degree of immediate bleeding seemed excessive in these 3 cases and prompt clip application was necessary. It should also be noted that clips were placed prophylactically in all cases even when no bleeding was observed.

Limitations of this study include the single-center, retrospective design in a primarily male Veteran population. Technical aspects which may have contributed to the low post-polypectomy bleeding rate include the widespread use of cold snare technique (snare without cautery), and the use of submucosal injection when cautery was applied. It is plausible, although unproven, that these methods reduce the risk of wall injury and subsequent delayed bleeding [11]. Immediate clip application is also of unproven benefit, particularly since a randomized study in average bleeding-risk patients did not show a benefit in prevention of post-polypectomy bleeding [18]. However, anecdotally we commonly observed increased oozing following cold snare polypectomy in patients taking clopidogrel compared to average-risk patients, and in the absence of data on the bleeding risks we felt compelled to proceed with routine immediate clipping in all cases.

In conclusion, this series suggests that it is possible to perform colonoscopic polypectomy on lesions up to $1 \mathrm{~cm}$ in size without interruption of clopidogrel. Given that only a small minority of patients undergoing screening colonoscopy have lesions larger than $1 \mathrm{~cm}$, it may be reasonable to consider performing screening examinations without stopping clopidogrel and rescheduling only those patients with larger lesions.

\section{Acknowledgements}

Author Contribution: Shai Friedland, Cynthia Leung and Roy Soetikno analyzed the data and wrote the manuscript. Financial Support: None. Conflict of Interest: None.

\section{References}

1. Savi P, Nurden P, Nurden AT, Levy-Toledano S, Herbert JM. Clopidogrel: a review of its mechanism of action. Platelets 1998;9(3-4):251-255.

2. Parikh SA, Beckman JA. Contemporary use of clopidogrel in patients with coronary artery disease. Curr Cardiol Rep 2007;9(4):257-263.

3. Atiemo AD, Williams MS. Clopidogrel use in coronary heart disease and percutaneous coronary intervention. J Investig Med 2008;56(4):689-700.
4. Douketis JD, Berger PB, Dunn AS, Jaffer AK, Spyropoulos AC, Becker RC, Ansell J. The perioperative management of antithrombotic therapy: American College of Chest Physicians Evidence-Based Clinical Practice Guidelines (8th Edition). Chest 2008;133(6 Suppl):299S-339S.

5. Lee SY, Tang SJ, Rockey DC, Weinstein D, Lara L, Sreenarasimhaiah J, Choi KW. Managing anticoagulation and antiplatelet medications in GI endoscopy: a survey comparing the East and the West. Gastrointest Endose 2008;67(7):1076-1081.

6. Zuckerman MJ, Hirota WK, Adler DG, Davila RE, Jacobson BC, Leighton JA, Qureshi WA, et al. ASGE guideline: the management of low-molecular-weight heparin and nonaspirin antiplatelet agents for endoscopic procedures. Gastrointest Endosc 2005;61(2):189-194.

7. Hui AJ, Wong RM, Ching JY, Hung LC, Chung SC, Sung JJ. Risk of colonoscopic polypectomy bleeding with anticoagulants and antiplatelet agents: analysis of 1657 cases. Gastrointest Endosc 2004;59(1):44-48.

8. Consolo P, Luigiano C, Strangio G, Scaffidi MG, Giacobbe G, Di Giuseppe G, Zirilli A, et al. Efficacy, risk factors and complications of endoscopic polypectomy: ten year experience at a single center. World J Gastroenterol 2008;14(15):2364-2369.

9. Friedland S, Leung CW, Sedehi D, Soetikno RM. Colonoscopy with Polypectomy in Patients Taking Clopidogrel. Gastroint Endosc 2008;67(5):AB289.

10. Tappero G, Gaia E, De Giuli P, Martini S, Gubetta L, Emanuelli G. Cold snare excision of small colorectal polyps. Gastrointest Endosc 1992;38(3):310-313.

11. Soetikno RM, Inoue H, Chang KJ. Endoscopic mucosal resection. Current concepts. Gastrointest Endosc Clin N Am 2000;10(4):595-617, vi.

12. Tricoci P, Roe MT, Mulgund J, Newby LK, Smith SC, Jr., Pollack CV, Jr., Fintel DJ, et al. Clopidogrel to treat patients with non-ST-segment elevation acute coronary syndromes after hospital discharge. Arch Intern Med 2006;166(7):806-811.

13. Fox KA, Goodman SG, Anderson FA, Jr., Granger CB, Moscucci M, Flather MD, Spencer F, et al. From guidelines to clinical practice: the impact of hospital and geographical characteristics on temporal trends in the management of acute coronary syndromes. The Global Registry of Acute Coronary Events (GRACE). Eur Heart J 2003;24(15):1414-1424.

14. Mood GR, Bhatt DL. Clopidogrel and risk for acute coronary events. Curr Atheroscler Rep 2007;9(5):401-408.

15. Hittelet A, Deviere J. Management of anticoagulants before and after endoscopy. Can J Gastroenterol 2003;17(5):329-332.

16. Kimchi NA, Broide E, Scapa E, Birkenfeld S. Antiplatelet therapy and the risk of bleeding induced by gastrointestinal endoscopic procedures. A systematic re- 
view of the literature and recommendations. Digestion 2007;75(1):36-45.

17. Sawhney MS, Salfiti N, Nelson DB, Lederle FA, Bond JH. Risk factors for severe delayed postpolypectomy bleeding. Endoscopy 2008;40(2):115-119.
18. Shioji K, Suzuki Y, Kobayashi M, Nakamura A, Azumaya M, Takeuchi M, Baba Y, et al. Prophylactic clip application does not decrease delayed bleeding after colonoscopic polypectomy. Gastrointest Endosc 2003;57(6):691-694. 